\title{
INFLUENCIAS DE LA MÚSICA PARA WESTERN DE DIMITRI TIOMKIN EN EL SPAGHETTI WESTERN
}

\author{
ÁNGEL JUSTO ESTEBARANZ \\ Universidad de Sevilla \\ LUCÍA PÉREZ GARCÍA \\ Universidad de Sevilla
}

\begin{abstract}
Resumen
La música del spaghetti western tiene una fuerte personalidad, conformada por ciertos elementos intrínsecos al momento de su creación y al género. Su principal representante es el compositor italiano Ennio Morricone. Ante la decadencia del western americano en la década de 1960, algunos de sus rasgos formales y musicales resultaron revolucionarios. Ello se debió al abandono de la tendencia dominante, impuesta por los norteamericanos Elmer Bernstein y Jerome Moross. Pero un análisis profundo de la historia de la música del western revela que algunos elementos considerados novedosos ya se daban en el western americano de los años 50 , concretamente en las composiciones de Dimitri Tiomkin. Al estudio de estos aspectos está dedicado el presente trabajo, donde se aportan los precedentes americanos y algunos ejemplos de su utilización en Italia.
\end{abstract}

\section{Palabras clave}

Dimitri Tiomkin, spaghetti western, Ennio Morricone, banda sonora, Estados Unidos, Italia, años 50, años 60.

Influences of western music by Dimitri Tiomkin in the spaghetti western

\section{Abstract}

The music of the spaghetti western has a strong personality, shaped by certain intrinsic elements at the time of its moment of creation and genre. Its main representative composer is Ennio Morricone. Given the decline of American westerns in the sixties, some of its formal and musical features were revolutionary. This was due to the abandonment of the dominant trend, imposed by the Americans Jerome Moross and Elmer Bernstein. But a thorough analysis of the history of western music reveals that some new elements considered already existed in the American western of the fifties, particularly in the compositions of Dimitri Tiomkin. To the study of these aspects is dedicated this work, where American precedents and examples of their use in Italy are provided.

\section{Keywords}

Dimitri Tiomkin, spaghetti western, Ennio Morricone, soundtrack, United States, Italy, 50s, 60s. 


\section{Introducción}

Fundamentación teórica

La música es un componente fundamental en el cine. Según Larsen, la música es parte de la película, parte de la experiencia cinematográfica y también parte del contexto cultural que rodea a la película ${ }^{1}$. Un elevado número de autores ha reconocido el importante papel que la música juega en el contexto fílmico, y han dedicado a su estudio una notable cantidad de textos, cuyo número ha aumentado exponencialmente desde los años $80^{-2}$. En el estudio de la música de cine se han adoptado distintos enfoques. Junto a textos clásicos como el de Adorno y Eisler, que indagaban en "la concreta relación de música y film con todas sus posibilidades y su contradicciones técnicas y sociales" ${ }^{3}$, han visto la luz estudios centrados en la historia de la música de cine ${ }^{4}$, mientras que otros combinaban un enfoque histórico con el estudio de aspectos de carácter teórico ${ }^{5}$. Ciertos autores han profundizado en la definición de las tipologías, en las características de esta música y su aplicación a la película ${ }^{6}$, optando por análisis de tipo semiótico que incide en el aporte de sentido de la música al film ${ }^{7}$. También se ha atendido a los usos comerciales de la música de películas, especialmente de la música popular ${ }^{8}$.

Ya en relación directa con la música del western, objeto de este trabajo, existen algunos estudios de conjunto como el volumen coordinado por Kalinak, aparecido en $2012^{9}$, y otros referidos a aspectos específicos como el publicado por la misma autora en 2007 sobre los westerns de John Ford ${ }^{10}$, el de Mariana Whitmer de 2012 para la música de Horizontes de grandez $a^{11}$, la tesis doctoral de Peter Graff sobre la música de los indios en los westerns de John Ford ${ }^{12}$ o el estudio de Roberto Cueto sobre el spaghetti western ${ }^{13}$.

En relación a la influencia que la música del western clásico americano tuvo sobre el spaghetti, en los diferentes estudios hay alusiones puntuales, identificándose apenas algún motivo melódico o ciertos timbres utilizados por Ennio Morricone y otros compositores italianos teniendo en cuenta los presentes en películas americanas. De forma más específica, Colón Perales, Infante Del Rosal y Lombardo Ortega han puesto de relieve la influencia directa de Tiomkin en Morricone y su partitura para Por un puñado de dólares (Sergio Leone, 1964). En esta obra se ha destacado la combinación muy personal de grupos vocales y orquestales, el uso provocativo de timbres poco usuales, el folclore norteamericano y la música pop "con el tejido de fondo del "Degüello" del Tiomkin de Rio Bravo y de El Álamo"14.

${ }^{1}$ Larsen, 2007: 7.

2 Larsen, 2007: 10.

3 Adorno/Eisler, 2005: 15.

${ }^{4}$ Cooke, 2008. Wierzbicki, 2009.

${ }^{5}$ Colón Perales/Infante Del Rosal/Lombardo Ortega, 1997.

${ }^{6}$ Larsen, 2007.

${ }^{7}$ Los análisis de Monelle en torno a determinados ritmos musicales como el de galope son extrapolables al cine, y más concretamente a la música del western. Véase Monelle, 2000. Asimismo, Blanco ha estudiado la importancia de la música en el cine en relación a la producción de sentido en un film, tratando unos pocos ejemplos entre los que figura Solo ante el peligro, película musicada por Dimitri Tiomkin, de la que trataremos en este artículo. Véase Blanco, 2010: 45-59.

8 Smith, 1998.

${ }^{9}$ Kalinak, 2012.

${ }^{10}$ Kalinak, 2007.

11 Whitmer, 2012.

12 Graff, 2013.

13 Cueto, 2002.

${ }^{14}$ Colón Perales/Infante Del Rosal/Lombardo Ortega, 1997: 66. 


\section{Objeto y objetivos del estudio}

El objeto de este estudio es la identificación de los aspectos presentes en la música para western de Dimitri Tiomkin que anticipan las características propias de la música del spaghetti. Intentamos caracterizar los elementos comunes al subgénero del spaghetti, presentando ejemplos de ellos a través de numerosas películas con música de Tiomkin y de compositores italianos, fundamentalmente Ennio Morricone. Se pretende hacer un análisis categorial comparativo, con el fin de sacar conclusiones acerca de la influencia de Tiomkin en la música del spaghetti.

\section{El spaghetti western}

El spaghetti western es un subgénero cinematográfico que tuvo unos inicios complicados en relación a su recepción crítica en tierras hollywoodienses ${ }^{15}$. Aunque celebrado con más o menos éxito en Europa, fue desprestigiado en Estados Unidos debido a su violencia explícita $^{16}$, e incluso fue tachado de absurdo ${ }^{17}$. Si estos calificativos se referían tanto a su temática como a su puesta en escena, su música no fue menos infravalorada, con comentarios despectivos de autores como Bosley Crowther, crítico poco afecto a coincidencias de otras cinematografías con lo que consideraba propio de América ${ }^{18}$. Era duro para Hollywood arrodillarse ante una evidencia de la cual fue en parte causante debido al desgaste del western americano y su renacimiento más allá de la "Frontera"19. Pero el tiempo acabó por rendirse a los pies de un género periférico que conquistó un espacio y una denominación propios ${ }^{20}$. También a los de su figura musical más prominente: Ennio Morricone. Abanderado de un estilo musical revolucionario que contagió a toda una generación de compositores (Bruno Nicolai, Luis Bacalov, Riz Ortolani, Carlo Savina, Piero Piccioni, Francesco de Massi, Gianni

15 Para este trabajo consideramos el inicio del Spaghetti Western a partir de los años sesenta, y principalmente de la irrupción de Sergio Leone, si bien en Italia se venían haciendo westerns desde los años de la Primera Guerra Mundial. Ejemplo de ello son La vampira india (Roberto Roberti, 1913), considerado el primer western italiano, dirigido, curiosamente, por el padre de Sergio Leone, o La reginetta dei butteri (Andrea Uccellini, 1922). Pero las características que aquellos presentaban no permiten incluirlas dentro de tan particular subgénero.

16 "Pero el hecho de que esta película esté construida para respaldar el ejercicio de los asesinos, enfatizar su bravuconería, y generar regocijo en las manifestaciones frenéticas de la muerte es, en mi opinión, una fuerte crítica de lo que viene a llamarse entretenimiento de un día. No hay nada saludable en matar a los hombres de forma gratuita, nada gracioso en verlos morir”. Véase Crowther, 1967.

${ }^{17}$ Sirva de ejemplo esta frase sobre Hasta que llegó su hora: "estrenada ayer en Loew's State 2 y Loew's Orpheum, es el western de Leone más grande, más largo, más caro y, en muchas formas, el más absurdo". Véase Canby, 1969.

18 Por un puñado de dólares, filmada con un color duro y sombrío, y al ritmo de una partitura musical que revela trucos y temas que suenan a copia (recuerda "Ghost riders in the sky"). Véase Crowther, 1967. La canción traída a colación por Crowther fue compuesta en 1948 por Stan Jones, siendo grabada por primera vez por Burl Ives en 1949, y más tarde por Johnny Cash. Lo cierto es que, a pesar de los prejuicios del crítico americano, existen ciertas diferencias relativas sobre todo a algunos timbres (salvo por la sempiterna guitarra), aunque ambas piezas están en modo eólico, lo que decantaría la opinión del autor. El salto de cuarta ascendente, y la continuación de la melodía por grados conjuntos (aunque en Morricone sea el silbido en vez de la voz de Cash) son rasgos que unen a las dos piezas. También lo es que la guitarra eléctrica repita el tema antes presentado por la voz humana (o su silbido).

${ }^{19}$ Desde los años cincuenta, la industria cinematográfica americana invirtió grandes cantidades de dinero en Italia, tanto en forma de coproducciones como en rodajes y distribución. Ejemplo de ello son los numerosos peplums rodados en los estudios de Cinecittá, de entre cuyos ayudantes de dirección y equipo técnico salieron algunos de los más reconocidos directores italianos del spaghetti: Sergio Leone, Sergio Corbucci o Mario Bava. Véase Eleftheriotis, 2001: 104.

${ }^{20}$ El término Spaghetti Western, inicialmente peyorativo, perdió sus connotaciones negativas allá por los años ochenta, si bien en Italia prefieren llamarlo "Western all'italiana". 
Ferrio, Franco Micalizzi...), Morricone se convertiría en insignia de la música del spaghetti western, sentando las bases de la banda sonora del Oeste italiano. Formado en el conservatorio romano de Santa Cecilia, fue precisamente su experiencia con la música popular la que permitió a Morricone dar el salto definitivo al cine ${ }^{21}$. Su participación en el "Gruppo Di Improvvisazione Nuova Consonanza", dedicado a la música experimental, y su faceta como arreglista de canciones ${ }^{22}$, constituven los cimientos de su, no menos experimental y popular, música para el western. Sería el arreglo para Peter Tevis de la canción de Woody Guthrie, "Pastures of Plenty" la que llamaría la atención de Sergio Leone. Morricone convirtió aquella canción en la música que acompañaba a los créditos iniciales de Por un puñado de dólares (1964) marcando ese año en el calendario de la Historia de la música cinematográfica. Había nacido para el cine el genial y prolífico Ennio Morricone ${ }^{23}$.

El italiano Francesco Lavagnino, compositor de spaghetti como Tohnny West (Gianfranco Parolini, 1965) o Réquiem para el gringo (Eugenio Martín y José Luis Merino, 1968), afirmaba que "la mayoría de las veces, la música que escribía para westerns era similar a la que hacían otros compositores italianos. 「... \ Morricone fue el primero en hacerlo, y lo hizo mejor que todos nosotros, porque tenía cosas nuevas que decir. No puedo decir lo mismo de mí" 24 . Al igual que en el campo formal, pues, la música del spaghetti adquirió características específicas e inconfundibles que se repitieron hasta la saciedad e, incluso, la autoparodia -con clara connotación humorística- en películas como Le llamaban Trinidad (Enzo Barboni, 1970), con música de Franco Micalizzi ${ }^{25}$. La mavoría, como hemos podido comprobar, producto de la inventiva de Morricone. Otras, interesantes aportaciones de Nicolai, Savina y otros seguidores.

Muchas de las características del spaghetti ya están presentes en el tema de la película Por un puñado de dólares (Sergio Leone, 1964, con música de Morricone), que sería referente para otros spaghetti. El análisis de esta música nos permite identificar los siguientes componentes:

-Vocalizaciones (uso de la voz sin palabras, con su timbre singular), tópicos ${ }^{26}$, susurros, ruidos irreconocibles, respiraciones, gritos...

-Silbidos.

-Nuevos instrumentos como la guitarra eléctrica.

-Percusiones novedosas: campanas, látigos, yunques...

-Amplificación de las posibilidades tímbricas de instrumentos como la armónica.

-Ruidos reales y de animales: galope, disparos, aullidos de coyote...

-Solos de trompeta en los momentos culminantes.

21 Anteriormente a sus grandes trabajos para el cine, Morricone trabajó como trompetista en una orquesta especializada en la música de cine. Véase Leinberger, 2004: 2.

22 Trabajó para la RCA en la época de auge de la canción italiana, arreglando temas de cantantes tan conocidos como Mario Lanza, Domenico Modugno, Paul Anka, Rita Pavone o Jimmy Fontana. Durante esa etapa, no solo conoció a algunos de los cantantes con los que luego colaboraría en sus películas, sino que tuvo que adaptarse a las consignas de las discográficas, como la adhesión a la tradición y el sonido cercano al público, o la importancia concedida al elemento rítmico, buscando siempre como fin último el éxito. Véase Plastino, 2014: 226-231.

${ }^{23}$ Con más de 500 bandas sonoras entre largometrajes para cine y televisión, documentales y cortos, continúa en activo en la actualidad, siendo su último trabajo precisamente un western, Los odiosos ocho (Quentin Tarantino, 2015) -ganador del Oscar en la edición 2015 de los premios de la Academia- y teniendo pendiente la película de Giuseppe Tornatore La Corrispondenza (2016). En su haber, cinco nominaciones a los Premios de la Academia y un Oscar honorifico por "sus magníficas y polifacéticas contribuciones al arte de la música cinematográfica". Para una información más detallada véase su perfil en IMDb, disponible en http://www.imdb.com/name/nm0001553/?nmdp=1\&mode=desktop\&ref_=m_ft_dsk [7/12/2015].

${ }^{24}$ Citado por Cueto, 2002: 111.

${ }^{25}$ Núñez Marqués, 2006.

${ }^{26}$ Nos referimos en este caso a lo que Raymond Monelle denomina "iconic topics", es decir, ítems musicales que remiten directamente a una imagen o icono, como por ejemplo el caballo u otros animales. Véase Monelle, 2000: 17-18 
-Uso de temas anempáticos.

-Empleo de la atonalidad para expresar la psicología de los personajes ${ }^{27}$.

-Predominio del silencio.

-Uso del modo dórico y eólico, y de la tonalidad de re menor ${ }^{28}$.

-Canciones introductorias interpretadas por vocalistas masculinos.

-Acercamiento a otros estilos como el pop o el jazz.

Dichas características, a priori tan alejadas de la tradición musical hollywoodiense, beben, sin embargo, del western clásico. El mismo Morricone contaba sobre uno de sus primeros encuentros con Leone: "La primera vez que Sergio escuchó una banda sonora mía fue en mi casa, y se aburrió soberanamente. Comentando cuando finalizó: 'Nunca podremos trabajar juntos'. [...] Pertenecía a Las Pistolas No Discuten y era una simple imitación del tipo de música de los westerns americanos, a lo Dimitri Tiomkin"29.

He aquí un punto de partida y un argumento sobre el que desarrollar un análisis con el que intentaremos demostrar cómo muchos de los elementos anteriormente enumerados ya estaban presentes, algunos en forma de esbozo y otros íntegramente, en las partituras de los westerns americanos de Dimitri Tiomkin. De hecho, aunque Leone se expresara en esos términos a priori, el director italiano había utilizado como "temp track" para su primer western el "Degüello" de Tiomkin, dato indicativo de sus intenciones, que sabría plasmar muy bien Morricone. A Leone le interesaba un sonido diferente, influido por algunas baladas folk americanas (arregladas por Morricone), pero el compositor tenía su bagaje y supo aprovechar algunas ideas de Tiomkin.

\section{Dimitri Tiomkin}

Nacido en Ucrania y formado en el conservatorio de San Petersburgo a las órdenes de Alexander Glazunov y Félix Blumenfeld, Dimitri Tiomkin (1894-1979) comenzó su carrera en Hollywood en 1929, contratado por Metro Goldwyn Mayer para poner música a las coreografías del ballet de su mujer Albertina Rasch. A sus espaldas llevaba decenas de recitales, espectáculos de ballet y vaudeville, por Europa y América, incluso habiendo trabajado en su juventud como acompañante musical de películas mudas. El bagaje era amplio y perfecto para enfrentarse a las necesidades de la música de cine. Compuso su primera banda sonora completa para la película Resurrección (Edwin Carewe, 1931). Pero su fama vendría apadrinada por el director Frank Capra, quien no solo le ofreció la oportunidad de trabajar en grandes producciones como Horizontes perdidos (1937) o iQué bello es vivir! (1946), sino que fue responsable de su introducción en el folclore americano ${ }^{30}$. En 1940 obtendría su primera nominación al Oscar por Caballero sin espada (Frank Capra), a la que le seguirían otras diecisiete, de las que saldría ganador en cuatro ocasiones ${ }^{31}$.

27 Valgan como ejemplo ciertos pasajes de la magnífica película El gran silencio (Sergio Corbucci, 1968), en la que Morricone combina unos temas en modo menor de enorme melancolía y sentido de la soledad con otros atonales que crean tensión y desasosiego.

28 Ambos modos están relacionados con estados anímicos muy acordes con el tono del spaghetti western. Según Ron Miller, el modo dórico es triste, incierto, pensativo y preocupado, mientras que el eólico es melancólico, triste, sombrío y oscuramente romántico. Véase Román, 2008: 144.

${ }^{29}$ Citado por Aguilar, 1999: 91.

30 "Me instó a estudiar la vieja música americana, canciones de las montañas de sur, himnos de Nueva Inglaterra, canciones de vaqueros, canciones del ferrocarril, me introdujo en una tradición que se remontaba a los días de las colonias". Tiomkin/Buranelli, 1959: 191.

31 Solo Ante el Peligro (Fred Zinnemann, 1952): mejor banda sonora comedia o drama y mejor canción; Escrito en el Cielo (William A. Wellman, 1954): mejor banda sonora drama o comedia; y El Viejo y el Mar (John Sturges, 1958): mejor banda sonora drama o comedia. 
Prolífico y exitoso en toda clase de géneros ${ }^{32}$, fue el western el que marcó su carrera. Primero con Duelo al sol (King Vidor, 1946) y Río Rojo (Howard Hawks, 1948), cuya música, pese a estar más cercana a la tradición americana, ya aportaba elementos novedosos. Más tarde, su partitura para Solo ante el peligro supondría un punto de inflexión en la música del western. Su concepción de la banda sonora basada en una canción, cuya melodía y letra van siguiendo el argumento, se impondría durante toda la década de los cincuenta ${ }^{33}$. Tan solo al final de la misma, el desgaste de la moda y la llegada de Jerome Moross y Elmer Bernstein con Horizontes de grandeza (William Wyler, 1959), y Los siete magnificos (John Sturges, 1960) respectivamente, acabarían con el reinado de Tiomkin en el western. Y sin embargo, todavía estaban por llegar películas como El Álamo (John Wayne, 1960), cuya influencia en el spaghetti western fue decisiva ${ }^{34}$.

Marcado por la faceta comercial de sus canciones ${ }^{35}$, no fue esta su única y más importante aportación al género del Oeste. También lo fueron el color, los timbres y las tonalidades. Tiomkin manejó con habilidad toda una serie de elementos y recursos musicales que se salían de la tradición clásica hollywoodiense. Consiguió que sus películas empezaran en pianissimo, llegó a eliminar las cuerdas de la práctica totalidad de la música de Solo ante el peligro ${ }^{36}$, utilizó instrumentos tradicionales americanos junto a la orquesta sinfónica, dándoles un mayor protagonismo; utilizó la voz humana de múltiples formas, simuló ruidos..., y todo ello sin dejar de ser, ante todo, "europeo".

\section{Metodología}

La metodología empleada para la elaboración de este trabajo es de carácter mixto deductivo-inductivo. Basándonos en las características de la música del spaghetti western apuntadas en la literatura sobre el tema, y de la experiencia en este tipo de estudios ${ }^{37}$, pudimos construir el sistema de categorías de análisis, que incluye los componentes musicales utilizados por Tiomkin en las obras para cine, y una vez establecida y comprobada su operatividad se procede a la tarea de análisis para determinar los componentes musicales de

32 Trabajó en multitud de ocasiones en el género de suspense, destacando las cuatro colaboraciones con Alfred Hitchcock: La Sombra de Una Duda (1943), Yo Confieso (1953), Extraños en un Tren (1951) y Crimen Perfecto (1954). Compuso bandas sonoras de películas de terror: El Enigma de Otro Mundo (Christian Nyby y Howard Hawks, 1951); cine negro: La Noche Eterna (Anatole Litvak, 1947); bélico: Los Cañones de Navarone (J. Lee Thompson, 1961) o los varios documentales propagandísticos de la Segunda Guerra Mundial; aventuras: Tarzán y las Sirenas (Robert Florey, 1948); comedia: Vive Como Quieras (Frank Capra, 1938); deporte: El Ídolo de Barro (Mark Robson, 1949); histórico: La Caída del Imperio Romano (Anthony Mann, 1964); animación: Rhapsody of Steel (Carl Urbano, 1959) y drama: Escrito en el Cielo (William A. Wellman, 1954).

${ }^{33}$ Lo que comenzó con Solo Ante el Peligro, llegó al culmen en Duelo de Titanes (John Sturges, 1957), donde la totalidad de la banda sonora está basada en la canción principal, la cual se divide, como la película, en tres actos. Los otros westerns de Tiomkin que siguieron más de cerca este modelo fueron: Soplo Salvaje (Hugo Fregonese, 1953), La Pelirroja Indómita (Mervyn Leroy, 1955) o El Último Tren de Gun Hill (John Sturges, 1959). Otras películas, si bien llevan una canción o tema principal, presentan una mayor variedad temática.

Entre otros, algunos de los westerns que siguieron su estela fueron: Johnny Guitar (Nicholas Ray, 1954), con música de Victor Young; El Hombre de Laramie (Anthony Mann, 1955) y El tren de las 3:10 (Delmer Daves, 1957), ambas con música de George Duning; o Centauros del Desierto (John Ford, 1956), con música de Max Steiner.

${ }^{34}$ Cumbow, 1982: 193. Padrol, 1998: 153.

35 Algunas de las canciones de Dimitri Tiomkin para el western consiguieron records de ventas, convirtiéndose no solo en una llamada para que el público asistiera a las salas de cine, sino en grandes éxitos comerciales que lanzaron y relanzaron la carrera de varios cantantes. Ejemplo de ello son las canciones de Solo ante el peligro, La gran prueba o Rawbide.

${ }^{36}$ No obstante, el tema que acompaña a Amy Kane sí lleva sección de cuerdas.

${ }^{37}$ En el trabajo "Del Japón feudal al planeta Akir: Estudio comparativo de la música en "Los siete samuráis" y sus remakes americanos" (2015) realizamos un análisis categorial que ha servido de base para este texto. Véase Justo Estebaranz/Pérez García, 2015: 159-166. 


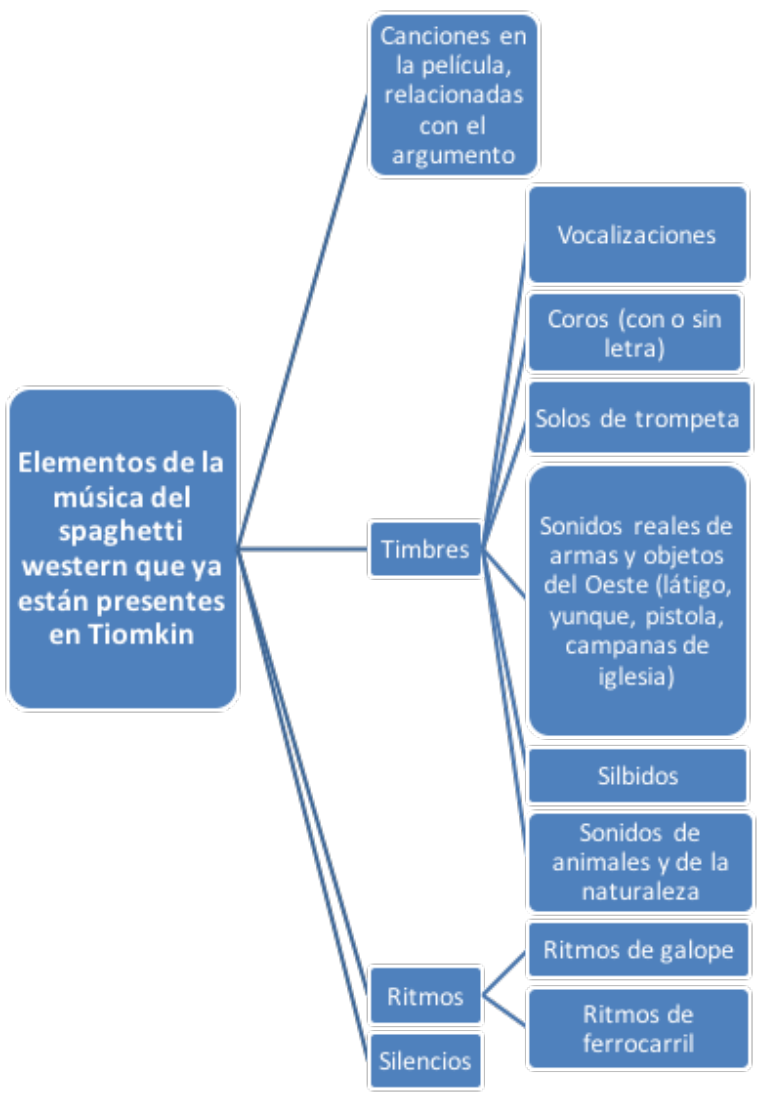

Fig. 1: Mapa semántico de los componentes musicales en los que Tiomkin se anticipa a la música del spaghetti western. Fuente: Elaboración propia.

una selección de películas del spaguetti werstern y de las películas musicadas por Tiomkin, y poder hacer una comparación entre ambas, tanto individualmente como en conjunto, de donde se han podido obtener las conclusiones. En la figura 1 presentamos el mapa semántico del sistema de categorías.

En cuanto a la muestra, hemos de señalar que incluye todas las películas del oeste con música de Dimitri Tiomkin -26-, y en relación con el spaguetti hemos realizado una selección cualitativa, buscando los ejemplos de los años 60y 70' más representativos en función de los siguientes criterios: calidad de la música, importancia de los compositores, influencia sobre otras partituras de films. Entre las películas italianas se han seleccionado las que se consideran obras maestras del subgénero -las de Leone con música de Morricone más algunas de Corbucci con partituras de Nicolai y otros- puesto que son las que van a establecer el canon seguido por infinidad de films de menor categoría. Pero junto a estas también incluimos otras de menor importancia cinematográfica, a fin de poder verificar que las características generales de la música del spaghetti se encuentran en la gran mayoría de películas del subgénero -29-. En total, las películas analizadas son 55, lo que se corresponde con un $47.27 \%$ de Tiomkin y un $52.73 \%$ de spaghetti westerns.

Por otra parte, en el análisis de las películas objeto de este estudio, además de aplicar a la muestra el sistema de categorías antes descrito, nos hemos apoyado en categorías establecidas por otros investigadores. Es el caso de la definición y funciones del uso de la música empática o anempática, formulada por Chion. Este autor definía el efecto anempático por contraposición al efecto empático. Si el empático es el efecto por el cual la música se adhiere directamente al sentimiento sugerido por la escena, el anempático se refiere al efecto de 
emoción multiplicada por el que la música "afirma su indiferencia, continuando su curso como si nada hubiera pasado" 38 . Sobre estos aspectos también ha reflexionado Xalabarder ${ }^{39}$.

Otro aspecto que hemos tenido en cuenta es la diferenciación entre la música diegética e incidental, así como la falsa diégesis. Sobre las categorías diegéticas se ha profundizado en textos como los de Kassabian o Alunno ${ }^{40}$. Tomamos como referencia las definiciones de Konigsberg y Xalabarder. Para Konigsberg, la música diegética en una película es aquella cuya procedencia resulta visible en pantalla, mientras que la incidental es la música de fondo que contribuye a crear un tono para la acción que está produciéndose o a transmitir los sentimientos de un personaje $\mathrm{e}^{41}$. Xalabarder atribuye a la música diegética un carácter realista, ubicando la música en un lugar concreto y con una duración exacta, mientras que considera la incidental como irreal, ubicada en lugares inconcretos y cuya duración no corresponde a criterios de exactitud ${ }^{42}$. En cambio, hay autores como Michel Chion que prefieren hablar de "música de pantalla" en vez de música diegética para aquella que es claramente oída como emanante de una fuente que esté presente o sugerida por la acción, dejando en cambio el término "música de fondo" - sustituto de "música no diegética"- para aquella que acompaña o comenta la acción y los diálogos, sin formar parte de ellos ${ }^{43}$. Este supuesto carácter realista de la música diegética defendido por Xalabarder, que disminuye en la dirección del nivel nodiegético, es para Alunno un concepto "pertinente solamente a la narración y no al contexto perceptivo de los espectadores o del aparato cinematográfico, para los cuales todo es al fin y al cabo diegético" $" 44$.

\section{Análisis de las influencias de Tiomkin en el spaghetti western y resultados}

El espectro de influencias procedentes del rico acervo de Tiomkin en el mundo de los films del Oeste es amplio y variado. Van desde la propia selección de instrumentos hasta algunos temas musicales, el uso de la voz en sus diferentes formas, recursos de carácter onomatopéyico, presencia de la música anempática, etc.

El resultado del análisis de las películas de la muestra aplicando el sistema de categorías representado en la figura 1 ha permitido obtener los resultados que presentamos organizados a través de las categorías señaladas.

\section{Uso de las canciones}

Durante los años 50', la canción folk va a ser un elemento casi obligatorio en el western americano. Sería precisamente Tiomkin quien, en Solo ante el peligro (1952), iniciara esta tendencia, aplaudida tanto por la industria cinematográfica como por la discográfica (debido a las buenas perspectivas comerciales). Los temas cantados por populares cantantes country tenían además la ventaja de añadir contenido extra al tejido dramático de la película (véase la Tabla 1). Algunas incluso proponen cuestiones acerca de la naturaleza del protagonista, como si se hicieran eco de las inquietudes de los personajes de la diégesis ${ }^{45}$.

38 Chion, 2010: 232-233.

39 Xalabarder, 2006: 37-38.

${ }^{40}$ Kassabian, 2009. Alunno, 2015: 15-24.

${ }^{41}$ Konigsberg, 2004: 347.

42 Xalabarder, 2006: 33-34.

43 Chion, 2010: 193.

${ }^{44}$ Alunno, 2015: 16.

45 Dimitri Tiomkin compuso un total de 36 canciones para los 26 westerns a los que puso música. De ellas, no todas aparecieron como tal en las películas, surgiendo posteriormente en su versión comercial, o quedando sobre el papel. Las que sí llegaron a formar parte integrante de la obra final fueron: "Settle down" de Río Rojo (Howard Hawks, 1948), "Matamoros" de Dakota Lil (Lesley Selander, 1950), "Quand je rêve" de Río de sangre (Howard Hawks, 1952), "Do not forsake me oh my darling" de Solo ante el peligro (Fred Zinnemann, 1952), "The ballad of black gold" de Soplo salvaje (Hugo Fregonese, 1953), "Jamie" de Una bala en el camino (John Farrow, 
Siguiendo la estela de Tiomkin, numerosos compositores, entre los que cabe citar a Harry Sukman ${ }^{46}$, Victor Young o George Duning, utilizaron el mismo recurso para muchos de sus westerns.

\begin{tabular}{|l|l|}
\hline \multicolumn{2}{|l|}{$\begin{array}{l}\text { EJEMPLOS SIGNIFICATIVOS DE CANCIONES } \\
\text { (eficacia dramática/comercialidad) }\end{array}$} \\
\hline Tiomkin & Spaghetti \\
\hline "Do not forsake me oh my darling" & "Angel face" \\
Solo ante el peligro (Fred Zinnemann, & Una pistola para Ringo (Duccio Tessari, 1965) \\
1952; fig. 2) & Compositor: Ennio Morricone \\
Intérprete: Tex Ritter & Intérprete: Maurizio Graf \\
\hline "Ballad Of Black Gold" & "A lone and angry man" \\
Soplo Salvaje (Hugo Fregonese, 1953) & Una tumba para el sheriff (Mario Caiano, 1965) \\
Intérprete: Frankie Laine & Compositor: Francesco De Masi \\
\hline "Strange lady in town" & Intérprete: Peter Tevis \\
La pelirroja indómita (Mervyn LeRoy, & "Il ritorno di Ringo" \\
1955) & El retorno de Ringo (Duccio Tessari, 1965) \\
Intérprete: Frankie Laine & Compositor: Ennio Morricone \\
\hline "Friendly Persuasión" & Intérprete: Maurizio Graf \\
La Gran Prueba (William Wyler, 1956) & "Johnny West" \\
Intérprete: Pat Boone & Johnny West (Gianfranco Parolini, 1966) \\
& Compositor: Angelo Francesco Lavagnino \\
\hline "Gunfight at the O.K. Corral" & Intérprete: Katyna Ranieri \\
Duelo de titanes (John Sturges, 1957) & "Johnny Oro" \\
Intérprete: Frankie Laine & Johnny Oro (Sergio Corbucci, 1966) \\
& Compositor: Carlo Sabina \\
\hline "Rawhide" & Intérprete: I Cantori Moderni di Alessandroni \\
Rawhide (1957-1961) & "Django" \\
Intérprete: Frankie Laine & Django (Sergio Corbucci, 1966) \\
\hline "My rifle, my pony and me" & Compositor: Luis Bakalov \\
"Rio Bravo" & Intérprete: Rocky Roberts \\
Río Bravo (Howard Hawks, 1959) & "The yankee fellow" \\
Intérprete: Dean Martin y Ricky & Cazador de recompensas (Tonino Valerii, 1966) \\
Nelson & Compositor: Nico Fidenco \\
& Intérprete: The Wilder Brothers \\
\hline & \\
\hline
\end{tabular}

1954), "Strange lady in town" de La pelirroja indómita (Mervyn LeRoy, 1955), "This then is Texas" de Gigante (George Stevens, 1956), "Friendly persuasion", "Indiana holliday", "Marry me, marry me", y "The mockingbird in a willow tree" de La gran prueba (William Wyler, 1956), "Follow the river" y "We can't get far without a railroad" de La última bala (James Neilson, 1957), "Gunfight at OK Corral" de Duelo de titanes (John Sturges, 1957), "Rawhide" de la serie de televisión Rawbide (1957-1965), "Strange are the ways of love" de The young land (Ted Tetzlaff, 1959), "Rio Bravo" y "My rifle, my pony and me" de Rio Bravo (Howard Hawks, 1959), "The green leaves of Summer", "Ballad of the Alamo", "Tennesse baby" y "Here's to the ladies" de El Alamo (John Wayne, 1960), "Gunslinger" de la serie de televisión Gunslinger (1961), "Pretty little girl in a yellow dress de El último atardecer (Robert Aldrich, 1961), y "The ballad of the war wagon" de Ataque al carro blindado (Burt Kennedy, 1967).

46 Sukman fue amigo personal de Tiomkin, y trabajó con él en Viento salvaje (George Cukor, 1957). Ambos intercambiaron correspondencia hasta el fallecimiento del ucraniano en 1979. "Ray Turner and Dimitri Tiomkin". Dimitri Tiomkin Official Website, August, 2015. http://www.dimitritiomkin.com/10866/august-2015ray-turner-and-dimitri-tiomkin/ (Consultada el 28/05/2016). 


\begin{tabular}{|c|c|}
\hline $\begin{array}{l}\text { "Strange are the ways of love" } \\
\text { The young land (Ted Tetzlaff, 1959) } \\
\text { Intérprete: Randy Sparks }\end{array}$ & $\begin{array}{l}\text { "There will come a morning" } \\
\text { Alambradas de violencia (León Klimovsky y Enzo G. } \\
\text { Castellari, 1966) } \\
\text { Compositor: Carlo Savina } \\
\text { Intérprete: Don Powell }\end{array}$ \\
\hline $\begin{array}{l}\text { "The green leaves of Summer" } \\
\text { "The ballad of the Alamo" } \\
\text { El Álamo (John Wayne, 1960) } \\
\text { Intérpretes: coros }\end{array}$ & $\begin{array}{l}\text { "Arizona Colt" } \\
\text { Arizona Colt (Michele Lupo, 1966) } \\
\text { Compositor: Francesco de Masi } \\
\text { Intérprete: Raoul }\end{array}$ \\
\hline $\begin{array}{l}\text { "Gunslinger" } \\
\text { Gunslinger (1961) } \\
\text { Intérprete: Frankie Laine }\end{array}$ & $\begin{array}{l}\text { "Texas, addio" } \\
\text { Adiós Texas (Ferdinando Baldi, 1966) } \\
\text { Compositor: Antón García Abril } \\
\text { Intérprete: Don Powell }\end{array}$ \\
\hline $\begin{array}{l}\text { "Pretty Little girl in a yellow dress" } \\
\text { El ultimo atardecer (Robert Aldrich, } \\
\text { 1961) } \\
\text { Intérprete: Kirk Douglas }\end{array}$ & $\begin{array}{l}\text { "Ballad of Johnny Yuma" } \\
\text { Johnny Y uma (Romolo Guerrieri, 1966) } \\
\text { Compositor: Nora Orlandi } \\
\text { Intérprete: The Wilder Brother }\end{array}$ \\
\hline $\begin{array}{l}\text { "Ballad Of The War Wagon" } \\
\text { Atraco al carro blindado (Burt Kennedy, } \\
\text { 1967) } \\
\text { Intérprete: Ed Ames }\end{array}$ & $\begin{array}{l}\text { "Death rides a horse" } \\
\text { De hombre a hombre (Giulio Petroni, 1967) } \\
\text { Compositor: Ennio Morricone } \\
\text { Intérprete: Raoul }\end{array}$ \\
\hline
\end{tabular}

Tabla 1: Presenta las canciones eficaces dramática y comercialmente incluidas en partituras para westerns de Tiomkin y ejemplos destacados de spaghetti que hacen uso del mismo recurso. Fuente: Elaboración propia.

Algunos spaghetti de los $60^{\prime}$ recurrirían a esta solución de vincular el tema principal de la película con una canción directamente relacionada con la trama. Pero esto sucedió no solo en genuinos spaghetti, sino también en coproducciones españolas con otros países realizadas al amparo de este subgénero y que presentaban las mismas características. Concretamente, nos referimos a La balada de Tohnny Ringo (José Luis Madrid, 1965), con música de Federico Martínez Tudó. En ella, se canta una balada cuya letra alude directamente al pistolero, interrogándose el cantante por la presencia o no del pistolero en la ciudad. En la italiana Una pistola para Ringo (Duccio Tessari, 1965), con música de Morricone, nos encontramos el tema "Angel face", que alude directamente al protagonista y a su sobrenombre, desde el primer momento. La influencia del spaghetti también alcanzará las canciones del western americano de finales de los sesenta. Ejemplo de ello es la canción "Old turkey buzzard", compuesta por Quincy Jones para El oro de Mackenna (I. Lee Thompson, 1969). Una canción que supone un curioso intercambio de influencias teniendo en cuenta que los productores de la película fueron Carl Foreman -que también escribió la letra de la canción bajo el pseudónimo de Freddie Douglas-, productor de Solo ante el peligro, y el mismo Dimitri Tiomkin.

Por otra parte, y en relación directa con las canciones, también hay que reconocer a Tiomkin la idea de la composición de temas musicales pensados para funcionar tanto dentro de la película -es decir, su eficacia dramática en el contexto fílmico- como más allá de ella, ya sea mediante su difusión radiofónica o, lo que será cada vez más importante, discográfica. Tal como señalan Colón Perales, Infante del Rosal y Lombardo Ortega, incluiría versiones comerciales de estos temas en la edición de las bandas sonoras, y en sus películas 
encontramos, de forma pionera, referencias a la edición discográfica en los títulos de crédito $^{47}$. En este sentido, Morricone sería un digno continuador de su figura ${ }^{48}$.

\section{Timbres}

El conjunto de timbres empleados en la música para spaghetti westerns es uno de los elementos más destacados a la hora de detectar influencias de las partituras de los 50' en las del cine del Oeste realizado en Italia. Tiomkin no solo añadió a la orquesta, de forma sistemática, instrumentos tradicionales como el banjo, la guitarra española, el guitarrón y el tololoche mexicanos, el arpa de boca, la armónica o el acordeón, sino que llegó incluso a suprimir la sección de cuerdas en Solo ante el peligro -algo impensable en el Hollywood clásico, a utilizar instrumentos de forma diferente, como el piano percusivo, y a componer temas tan solo con este tipo de instrumentos, como el leitmotiv de Jett Rink en Gigante (George Stevens, 1956). Esta decisión luego sería asumida por los compositores italianos de los años $60^{\prime}$, al menos en algunos temas. Estos, empezando por Morricone, prescindirán en muchas ocasiones de la orquesta, creando temas a base de ritmos y sonidos de instrumentos tanto tradicionales como totalmente novedosos, e incluso exóticos. Tal como señalaba Robert Cumbow en relación a este aspecto en la música de Morricone: "Gran parte de lo asombroso de las partituras de Morricone para Leone deriva del enfoque excéntrico de la orquestación. Su asociación del silbido humano con el solitario errante (en cinco westerns) es el más melódico de los recursos que utiliza para crear música no orquestal: el isproing! del arpa de boca (o birimbao), el wah-wah de la armónica amplificada, los latigazos, disparos y un arsenal exótico de menos identificables twags, bangs, clicks y clangs, caracteriza su salvaje orquestación" ${ }^{49}$.

Otros recursos tímbricos destacados en las partituras para westerns de Tiomkin son el uso de la voz humana de formas variadas, la simulación del ritmo de galope y del ferrocarril, o la imitación e inclusión de sonidos reales y de animales, entre otros. Muchos de estos recursos, como veremos, adelantaron algunos de los procedimientos que más tarde se considerarían propios del spaghetti western.

El primero y más relevante es la voz bumana. Las partituras de Tiomkin revelan un intenso aprecio por la voz humana, la cual le gustaba emplear tanto como a Morricone ${ }^{50}$. Tanto uno como el otro -y como los seguidores italianos de Morricone- emplearían la voz humana de diferentes maneras.

Como hemos comentado, casi todos los westerns de Tiomkin llevan una canción asociada. Para su interpretación, Tiomkin acudió normalmente a cantantes masculinos de voz grave, mucho más acorde con un género normalmente protagonizado por hombres de recio carácter y duros modales: Tex Ritter, Frankie Laine, o las más melodiosas voces de Pat Boone

47 Colón Perales/Infante Del Rosal/Lombardo Ortega, 1997: 119.

${ }^{48}$ La compañía discográfica RCA editaba las bandas sonoras de las principales películas estrenadas, coincidiendo con el desarrollo de la carrera de Morricone. Ya en los años 70', la venta de música de cine suponía un $30 \%$ de las ventas de discos en Italia, figurando entre los mayores éxitos los del compositor romano. Véase Cueto, 2002: 105.

El mercado italiano, durante los años 60', fue particularmente fértil en cuanto a la edición de singles y LPs de spaghetti western. Discográficas como CAN o RCA sacaron un prestigioso y elaborado catálogo de títulos que demostraban el interés y respeto del público italiano. Núñez Márquez, 2006: 415.

${ }^{49}$ Citado por Leinberger, 2004: 62.

50 Morricone reconocía este amor personalmente: “Amo la voz humana porque es un instrumento extraordinario. No viene de una pieza de madera o de metal, sino que sale directamente del cuerpo y puede ser el instrumento más maleable y expresivo. Puede reaccionar de muchas maneras. Primero, uso la voz humana porque la amo; y segundo, la uso porque tengo una voz excepcional a mi disposición (Edda Dell'Orso)... por lo que me he convertido en alguien que utiliza la voz humana continuamente”. Véase Leinberger, 2004: 22. 
y los actores cantantes Dean Martin o Frankie Avalon ${ }^{51}$. Más tarde, el western italiano estará plagado de canciones basadas en las baladas americanas, y cuyos principales intérpretes serán hombres, entre los que destacan voces como las de Peter Tevis o de Raoul, ambos comparados a sus homólogos americanos ${ }^{52}$. Tanto Tiomkin como los italianos emplearán en la mayor parte de las ocasiones tonalidades menores para componer sus canciones.

Otro recurso vocal al que Tiomkin acudió constantemente fue el de la utilización de los coros, que también aparecen de forma destacada en los ejemplos transalpinos de los años $60^{\prime}$. Tiomkin contaba entre sus más fieles colaboradores con el director de coro Jester Hairston. El uso que hace del coro no se limita a la interpretación de los temas principales sino que, al igual que posteriormente harán Morricone y sus seguidores, también lo emplea como un instrumento más, sin recurrir a apoyo literario de ningún tipo, a través de las vocalizaciones (véase Tabla 2): enfatizando momentos solemnes, como el de la oración de la cosecha de El Forastero o la muerte de Laura Bell en Duelo al Sol, en ambos casos con las voces femeninas sobresaliendo sobre las masculinas; uniéndose al crescendo orquestal en los créditos finales de Rio Rojo (Howard Hawks, 1948) o Retaguardia (David Butler, 1954); en forma onomatopéyica, simulando el ruido del carro en Ataque al carro blindado (Burt Kennnedy, 1967); marcando el ritmo a modo de percusión en Duelo de titanes o Rawbide, de forma salvaje y fantasmal en el tema "Squaw head's rock" de Duelo al sol, a base de gritos en Rawhide, gritando, susurrando...

Este recurso de la vocalización va a ser una constante tanto en las partituras de Morricone -véase como mejores ejemplos los de la Trilogía del dólar, pero también otros como Joe, el implacable (Sergio Corbucci, 1966)- como en las de sus seguidores, muy especialmente Bruno Nicolai, quien dirigió las partituras de Morricone hasta que comenzó a componer las suyas propias. Este haría un uso muy similar al del maestro en la partitura de la película Buon funerale, amigos!... paga Sartana (Giuliano Carnimeo, 1970) ${ }^{53}$.

El silbido, una de las características más destacadas de las partituras de los westerns de Morricone, y que también puede incluirse dentro de la voz humana, aparecía ya en los créditos iniciales de Duelo de titanes, introduciendo el tema principal y acompañando posteriormente algunos de los versos. También de forma diegética podemos ver a algunos personajes silbando el tema principal correspondiente en un momento ocioso. Así ocurre con Dude y Colorado en Río Bravo, o con Ida y Paddy en Tres vidas errantes (Fred Zinnemann, $1960)^{54}$. En los spaghetti, el silbido

será una constante. Tenemos los ejemplos de la Trilogía del dólar y, junto a ellos y entre tantos otros, la partitura de Sartana, antes mencionada, o la de Adiós Sabata, también de Nicolai $^{55}$. En estas bandas sonoras sería el silbido de Kurt Savoy el habitual.

\footnotetext{
51 Solo en una ocasión pensaría en una voz femenina. Fue para la canción de El último tren de Gun Hill, para la que pensó en la cantante afroamericana Kitty White. Pero, finalmente, la canción fue eliminada de la película, quedando tan solo su versión comercial.

52 Para Roberto Cueto, "si Tevis era el Tex Ritter italiano, Raoul era, indudablemente, el Frankie Laine latino". Cueto, 2002: 113.

${ }^{53}$ En esta obra se puede escuchar también la guitarra eléctrica, con la figuración rítmica de galope, y la trompeta. El solo está tocado por Alessandroni, y las voces son de Cantori Moderni. Y junto a estos recursos, el silbido.

${ }^{54}$ No solo en el western. Tiomkin empleó el recurso del silbido como timbre destacado en películas de otros géneros. Ejemplo de ello es Escrito en el cielo (William A. Wellman, 1954), por la que consiguió un Oscar, donde el personaje de John Wayne silbaba continuamente el tema principal de tal forma que se creaba una fusión, y confusión, entre lo diegético y lo incidental.

${ }^{55}$ En ella, otra vez la guitarra eléctrica, y los coros sin palabras, pero también los susurros (que repiten "Indio Black", el título original de la película). El título entero es Indio Black, sai che ti dico: Sei un gran figlio di... La película, segunda de la trilogía de Sabata, es obra de Gianfranco Parolini (1970).
} 
Influencias de la música para western de Dimitri Tiomkin en el spaghetti western

\section{EJEMPLOS SIGNIFICATIVOS DEL EMPLEO DE VOCALIZACIONES}

\begin{tabular}{|c|c|}
\hline Tiomkin & Spaghetti \\
\hline Duelo al sol (King Vidor, 1946) & $\begin{array}{l}\text { Plazo para morir } \\
\text { (Giovanni Grimaldi, 1965) } \\
\text { Compositor: Nico Fidenco }\end{array}$ \\
\hline Rio Rojo (Howard Hawk, 1948) & $\begin{array}{l}\text { Trilogía del dólar } \\
\text { (Sergio Leone, 1964-65-66) } \\
\text { Compositor: Ennio Morricone }\end{array}$ \\
\hline Duelo de titanes (John Sturges, 1957) & $\begin{array}{l}\text { Johnny Yuma } \\
\text { (Romolo Guerrieri, 1966) } \\
\text { Compositor: Nora Orlandi }\end{array}$ \\
\hline Rawbide (1957-1961) & $\begin{array}{l}\text { Joe, el implacable } \\
\text { (Sergio Corbucci, } 1966 \\
\text { Compositror: Ennio Morricone }\end{array}$ \\
\hline Gunslinger (1961) & $\begin{array}{l}\text { Tierra de gigantes } \\
\text { (Ferdinando Baldi, 1969) } \\
\text { Compositor: Roberto Pregadio }\end{array}$ \\
\hline $\begin{array}{l}\text { Ataque al carro blindado (Burt Kennedy, 1967) } \\
\qquad \text { Tabla 2: Presenta las obras de }\end{array}$ & 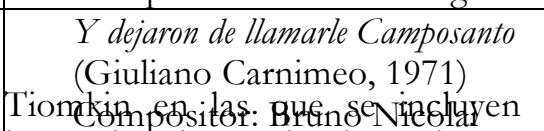 \\
\hline
\end{tabular}

Otro de los recursos que podemos destacar dentro de este apartado del color instrumental es la figuración rítmica de galope. Este elemento, implícito en la música tradicional americana a base de ostinati rítmicos ${ }^{56}$, está presente en varios de los westerns de Tiomkin de formas variadas. Además de servir de base rítmica para los temas a los que acompaña, los contextualiza dentro de un lugar, una época y un género: el western, donde los caballos son un elemento primordial y obligatorio. Como parte de la música, los italianos lo utilizarían en su forma real, mientras que Tiomkin va a emplear la percusión para crear una figuración rítmica que remite al galope, siendo la caja china la solución más recurrente: en el tema "The rye waltz" de Duelo al sol, en el tema principal de La pelirroja indómita, Duelo de titanes, en el de Río Bravo o en el de Ataque al carro blindado. Los temas principales son muy dados a este tipo de soluciones debido a la forma tradicional de iniciar los westerns con una secuencia de uno o más vaqueros acercándose desde el horizonte. Tiomkin, además de ritmos de galope, utilizó otros recursos como el ritmo de ferrocarril, que sustituye a los caballos como elemento fundamental de la trama en Solo ante elpeligro ${ }^{57}$. Precisamente al tratar del galope y del ritornelo, el filósofo Gilles Deleuze señalaba que en westerns tales como Solo ante el peligro, la frasecita melódica venía a interrumpir los ritmos galopantes ${ }^{58}$, lo cual no nos parece acertado, pues en esa película no hay propiamente ritmos de galope, sino del tren.

${ }^{56}$ Edith Lang y George West, dentro de sus consejos para los pianistas y organistas que acompañaban las películas mudas, proponían para simular el galope del caballo cualquier pieza en 6/8 y ritmo Allegro, o algunos temas preexistentes como la "Cabalgata de las Valquirias" de Wagner o la "Caballería Ligera" de Von Suppé. Véase Lang/West, 1920: 58.

${ }^{57} \mathrm{El}$ ritmo de ferrocarril en Solo ante el peligro se cuenta entre los elementos novedosos de la banda sonora, al estar producido no por instrumentos de percusión, sino por un novachord, instrumento considerado como el primer sintetizador polifónico, y que fue bastante utilizado por compositores como Franz Waxman. Véase Neumeyer, 2014: 138; Walker, 2015: 353.

${ }^{58}$ Citado por Mouëllic, 2011: 84. 


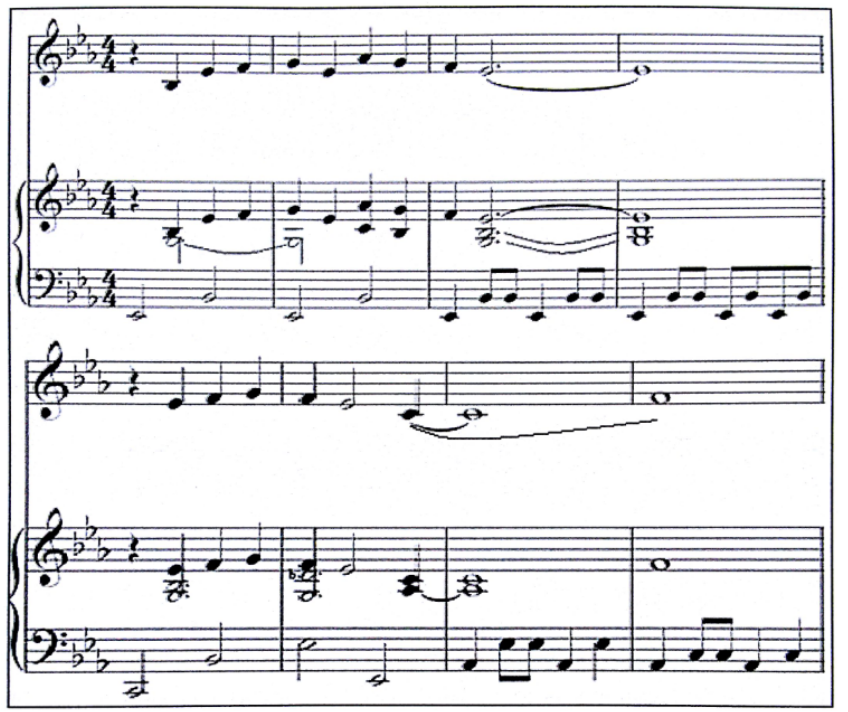

Fig. 2: Transcripción para piano y voz de "Do not forsake me oh my darling" de Solo ante el peligro (1952), en la que se puede observar la figura que simula el traqueteo del ferrocarril. Transcripción propia.

Morricone utilizó casi de manera sistemática este elemento dentro de sus bandas sonoras, si bien empleando una figura musical diferente a la de Tiomkin. Mientras que el ucraniano

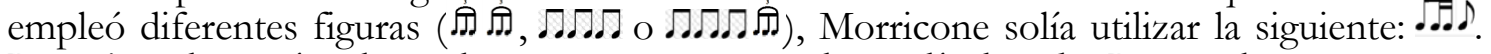
Los ejemplos más claros los encontramos en las películas de Leone: los temas que acompañan a los créditos iniciales de la Trilogía del dólar ${ }^{59}$ y el leitmotiv de Cheyenne en Hasta que llegó su hora (1968). En la persecución del grupo de bandidos tras el robo en Una pistola para Ringo (Duccio Tessari, 1965), Morricone emplea la figuración rítmica de galope, esta vez acompañando una melodía de recuerdos mexicanos, en alusión a la procedencia de Sancho y sus secuaces ${ }^{60}$.

Los sonidos reales ${ }^{61}$ son otro de los elementos que aparecen tempranamente en los westerns de Tiomkin y que demuestran su capacidad creativa. Destacan el disparo que inicia los créditos de Duelo al sol, recurso que Morricone utilizaría dos décadas más tarde en los créditos de la Trilogía del dólar de Sergio Leone; y el sonido del látigo del tema principal de la serie Rawbide, un sonido que aparecerá en multitud de westerns posteriores, tanto italianos como americanos, y que Morricone utilizará ya en Por un puñado de dólares. Morricone empleará los sonidos reales de una forma especial -principalmente en las secuencias de los duelos-, fundiendo la diégesis con la música incidental, como haría con el reloj de bolsillo de La muerte tenía un precio o con los ruidos de la secuencia inicial y la armónica de Hasta que llegó su hora. Esta relación entre música diegética e incidental creará en el espectador una sensación de inmersión mucho más intensa ${ }^{82}$. Sin embargo, este uso ya fue adelantado por Tiomkin en

59 Por un Puñado de Dólares (1964), La Muerte Tenía un Precio (1965) y El Bueno, El Feo y El Malo (1966).

${ }^{60} \mathrm{El}$ tópico del ritmo de galope se convirtió en un elemento recurrente de la música a partir de 1790, con hitos como "Der wilder reiter" de Robert Schumann, o el "Der erlkönig" de Franz Schubert. Consiste en una figura, más o menos rápida, compuesta por un doble o triple ritmo, cuyo significado tiene connotaciones culturales y literarias que derivan del "nobel corcel" medieval: activo, viril y aventurero. Véase Monelle, 2006: 5. El caballo en el western no deja de ser un animal noble, fiel compañero de aventuras de todo hombre del Oeste que se precie. En este caso, tenemos un ejemplo muy ilustrativo del uso de este tópico romántico en el western. Nos referimos a la "Obertura de Guillermo Tell” de Rossini, icónica melodía de El llanero solitario. Así pues, mientras Tiomkin se acerca más a este tipo de figuraciones, con alguna que otra variación, Morricone es absolutamente original al respecto.

${ }^{61}$ Con este término nos referimos a sonidos no producidos por instrumentos musicales o "sonadores" habituales.

${ }^{62}$ Núñez Marqués, 2006: 26. 
westerns como Solo ante el peligro, donde el silbido diegético del tren se integraba en el tema "Two minutes two twelve".

También los sonidos de animales y de la naturaleza hacen acto de presencia en las partituras del ucraniano, la mayor parte de las veces de forma simulada. Ejemplo de ello son el tema "Stampede" de Río Rojo, en el que la sección de metal simula los mugidos de los asustados animales, mientras que las cuerdas crean un movimiento desaforado en el que parece imposible contener la estampida del título; o la bandada de pájaros que simboliza la libertad de los hermanos Zachary en la escena final de Los Que No Perdonan (John Huston, 1960), para los que utiliza el sonido agudo de la flauta, cuyas escalas ascendentes y descendentes parecen soltar las pesadas cadenas de prejuicios que arrastraban los protagonistas.

Morricone hizo un uso diferente de los sonidos animales. Mientras en los westerns de Tiomkin aparecían como sustitutos de la realidad diegética, o en forma de mickeymousing, en los del italiano figuran como un instrumento más, e incluso en forma de leitmotiv, como ocurre en El Bueno, El Feo y El Malo, donde el aullido del coyote, con tres timbres diferentes, se convierte en el símbolo musical de los tres protagonistas ${ }^{63}$.

Por último, debemos mencionar otros rasgos en los que la música americana para westerns se adelanta a la tónica habitual en Italia: el uso de la guitarra eléctrica en el western americano de los años cincuenta y principios de los sesenta, antes de la llegada del eurowestern a Estados Unidos ${ }^{64}$. Eso sí, no en la obra de Tiomkin, sino en la de otros autores que trabajaron en el Hollywood de la época. Nos referimos a las composiciones Harry Sukman para Fury at showdown (Gerd Oswald, 1957) y Cuarenta pistolas (Sam Fuller, 1957), y las de Jerry Goldsmith para Rio Conchos (Gordon Douglas, 1964) y Bandolero (Andrew V. McLaglen, 1968). Así mismo, el compositor británico John Barry grabó en 1961 una versión con guitarra eléctrica del tema de Los Siete Magnificos de Elmer Bernstein. Todos ellos conforman un magnífico ejemplo de innovación formal, y de cómo este instrumento fue introducido en el western antes de que la Trilogía del Dólar de Morricone hiciera estragos en la música cinematográfica, provocando una tendencia general hacia el uso de este instrumento en el género del Oeste ${ }^{65}$. No en vano, muchos autores han señalado la influencia de Fuller en Leone ${ }^{66}$.

Solos de trompeta

Uno de los elementos más característicos de la música del spaghetti son los solos de trompeta que acompañan el momento culminante: el duelo final. Como la mayor parte de las convenciones, esta también deriva del repertorio de Morricone, trompetista e hijo de trompetista. Estos solos de trompeta se caracterizan por su sabor mariachi, por el uso de tonalidades menores, con preferencia por el modo eólico en Re; y por sus bellísimas melodías. Todo ello, unido al ritmo pausado y al montaje alternante entre primeros primerísimos planos y planos generales, dota a los duelos de una atmósfera solemne y de muerte, sin restar un ápice de tensión.

Ahora bien, Morricone tuvo un modelo directo para estos pasajes: el "Degüello" de Tiomkin que se escucha en Río Bravo y El Álamo. Esta pieza resultó decisiva en la concepción

${ }^{63}$ La flauta para el Bueno, la ocarina para el Feo y la voz humana para el Malo.

64 Por un Puñado de Dólares (Sergio Leone, 1964) se estrenó en Los Ángeles el 18 de enero de 1967. http://www.tcm.com/tcmdb/title/3645/A-Fistful-of-Dollars/original-print-info.html [29/05/2016].

${ }^{65}$ Casi todos los compositores del Spaghetti utilizaron la guitarra eléctrica en los temas que acompañaban a los créditos iniciales de sus películas. Algunos ejemplos son: Nico Fidenco en Cazador de Recompensas (Peril Giusto di Uccidare; Tonino Valerii, 1966); Riz Ortolani en El Día de la Ira (Il Giorni dell'Tra; Tonino Valerii, 1967); Roberto Pregadio en Tierra de Gigantes (Il Pistolero dell'Ave Maria; Ferdinando Baldi, 1969); o Bruno Nicolai en Llega Sartana (Una nuvola di polvere... un grido di morte... arriva Sartana; Giuliano Carnimeo, 1971).

${ }^{66}$ Cumbow, 2008: 144. Gili, 2006: 148. Giddins, 2010: 103. Meuel, 2015: 82.

Incluso algunos encuentran la relación más concretamente en Cuarenta Pistolas: Simmon, 2003: 276. Yoggy, 1998: 121. 


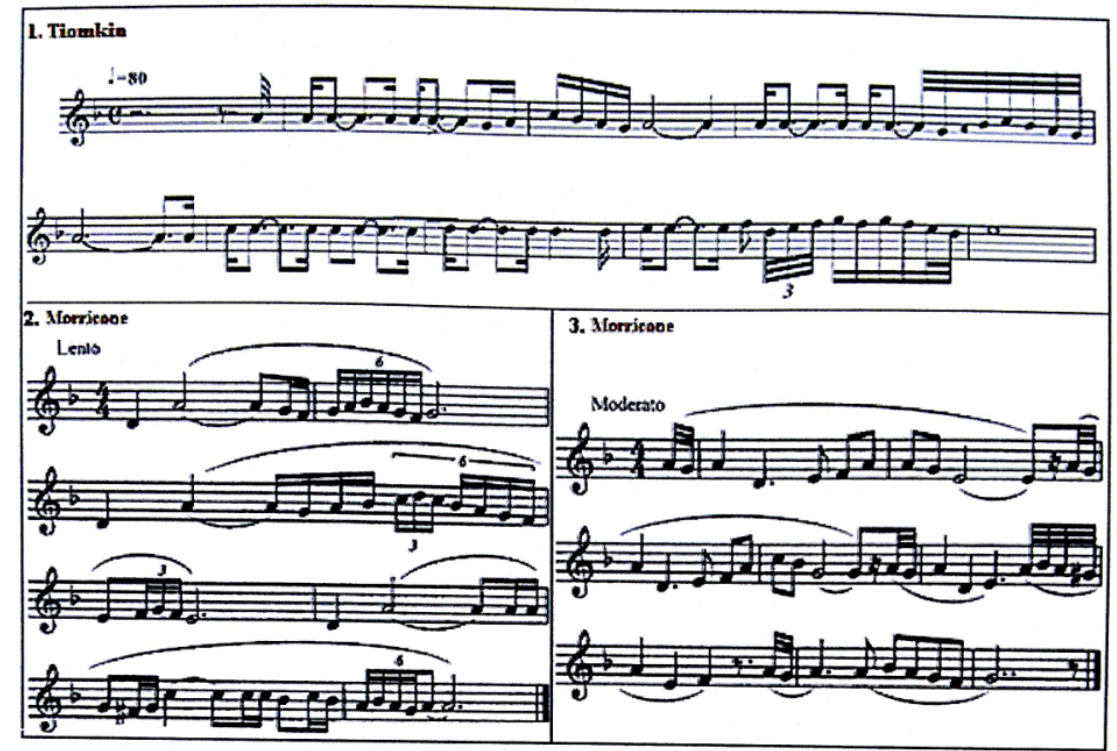

Fig. 3: 1. "Degüello" de El Álamo (1960) de Dimitri Tiomkin; 2 y 3. Solos de trompeta de los duelos finales de Por un puñado de dólares (1964) y La muerte tenía un precio (1965) de Ennio Morricone. Montaje realizado a partir de las partituras de Ennio Morricone tomadas de Leimberger, 2004, y de la trascripción propia del "Degüello" de Dimitri Tiomkin.

de este elemento. Y lo fue no solo en lo que respecta a la cuestión técnica y sonora, sino t ambién en simbolismo y significado: sin piedad, sin cuartel. Sergio Leone lo propuso como "temp-track" para Por un puñado de dólares ${ }^{67}$ a partir del cual Morricone compuso su propio tema: "es la trompeta la que suena como "Degüello", no es que el tema sea "Degüello",68. Desde entonces, el solo de trompeta se convirtió en señal distintiva del duelo del spaghetti western: "un bolero macabro antes de la muerte" " se dejó sentir en una doble vía: por un lado, en los aspectos puramente musicales -las melodías de uno y otro son parecidas; comparten tonalidad y profusión de florituras- (fig. 3); y por otro, en el significado, ya que en ambas se anticipa un clima de violencia y muerte. La diferencia estriba en la escala, teniendo el spaghetti (donde se suelen dar duelos) una mayor similitud en este aspecto con Río Bravo, donde los bandos enfrentados presentan un número más reducido de componentes que en El Álamo, en la que el enfrentamiento se produce entre dos ejércitos.

Tras Morricone, muchos otros compositores italianos siguieron esta convención. Uno de los más destacados en este sentido fue Bruno Nicolai, no por casualidad director de muchas de las composiciones del romano ${ }^{70}$. Django dispara primero (Alberto de Martino, 1966) o Cisco (Sergio Bergonzelli, 1966), más los otros títulos que hemos mencionado antes en este trabajo, son dignos ejemplos de ello. Pero no fue el único. Así, Michele Lacerenza compuso un tema totalmente "morriconiano" para el duelo de Baño de sangre al salir del sol (Alberto Cardone, 1966). O también Marcello Giombini, quien presenta con la trompeta el tema principal de la

${ }^{67}$ Cueto, 2002: 103.

${ }^{68}$ Ibidem.

${ }^{69}$ Hugues, 2010: 44.

${ }^{70} \mathrm{Su}$ parecido era tal que incluso se llegó a pensar que era un pseudónimo de Ennio Morricone. Cueto, 2002: 111. 
primera película de la Trilogía de Sabata, la mítica Ehi amico ... c'è Sabata, hai chiuso! (Gianfranco Parolini, 1969).

\section{Uso del silencio}

"El silencio puede ser una sentencia rotunda en una película; utilizado correctamente puede ser emocionalmente poderoso" "71. Esta afirmación de Fred Karlin es compartida por teóricos y compositores, para los que una buena banda sonora debe contemplar no solo los momentos musicales, sino aquellos en los que la ausencia de música refuerza la eficacia dramática. Tal es así que, como afirma Conrado Xalabarder, en ocasiones "los mayores aplausos que se ha llevado una música son debidos a una secuencia en la que no había ni una sola nota" . Para justificar este recurso, Michel Chion expone que "la música en el cine tiene que ver también con efectos de intermitencia, de interrupción, de silencio abiertos en el continuo verbal, en el que su presencia resuena de una manera particular," ${ }^{73}$. Y es que el cine debe mucho a esa resonancia, a esa llamada de atención que pone en alerta al espectador, emocional y físicamente.

El western es uno de los géneros en los que el silencio cobra una especial relevancia. La soledad del eterno horizonte, las peleas, tiroteos y batallas en los que golpes, pistolas y fusiles hablan por sí solos... paisaje, soledad, acción y violencia. Elementos que piden -a gritos- un poco de silencio. No por casualidad, uno de los maestros del género, John Ford opinaba: "odio ver a un hombre solo en el desierto, muriendo de sed, con la orquesta de Filadelfia detrás de él" "74.

Pero el silencio es diferente a un lado y otro del Atlántico. En el western clásico, las grandes partituras orquestales llenaban la casi totalidad del metraje. Los estudios imponían sus reglas. Hollywood era todo grandilocuencia y testarude $z^{75}$. Solo algunos westerns de serie $\mathrm{B}$ en los que se daba una mayor libertad a la hora de componer ${ }^{76}$, y algunos compositores y directores, plantaron cara a esta regla. Una regla que se fue diluyendo con los años, hasta alcanzar su culmen en la década de los setenta, con los últimos resquicios del western clásico y la aparición del western crepuscular ${ }^{77}$. Algunos de los westerns musicados por Tiomkin sobrepasan el $50 \%$ de silencio sobre el metraje total ${ }^{78}$. Incluso se da el caso de dos de ellos que superan el $60 \%{ }^{79}$. De entre ellos, es el último (Ataque al carro blindado), el más cercano al spaghetti en este sentido, al componerse de pequeños módulos musicales que dejan un margen de un $67.98 \%$ al silencio.

${ }^{71}$ Karlin, 1994: 11.

72 Xalabarder, 1997: 26.

${ }^{73}$ Chion, 1997: 235.

${ }^{74}$ Kalinak, 2004:125.

${ }^{75}$ En opinión de Jerry Goldsmith: "La razón por la que tantas partituras de Max Steiner son tan largas es que Warner ordena que sea así. Steiner argumentó en ocasiones que las películas serían mejores con menos música, pero su opinión fue rechazada”. Citado por Karlin, 1994: 12.

${ }^{76}$ Esto no es cierto para la generalidad de los westerns de serie B, la mayoría de los cuales estaban repletos de música diegética o de orquestaciones en imitación de las grandes producciones. Un ejemplo interesante en el uso del silencio es Fury at showdown (Gerd Oswald, 1957), cuya banda sonora está compuesta por Harry Sukman. El potente inicio con la guitarra eléctrica supone un contrapunto dramático al silencio posterior. Algo similar a los temas iniciales de los spaghetti, que se hacían de esta forma mucho más notables.

${ }_{77}$ Esta evolución en la cuestión del silencio se observa a la perfección en los western de Howard Hawks, cuyo análisis revela una tendencia al menor uso de la música.

${ }^{78}$ El forastero (William Wyler, 1940), Canadian Pacific (Edwin L. Marin, 1947), Río de sangre (Howard Hawks, 1952), La gran prueba (William Wyler, 1956), Duelo de titanes (John Sturges, 1957), Rio Bravo (Howard Hawks, 1959) y Los que no perdonan (John Huston, 1960).

${ }^{79}$ Tres vidas errantes (Fred Zinnemann, 1960) y Ataque al carro blindado (Burt Kennedy, 1967). 
Es en el spaghetti western donde el silencio se va a convertir en uno de los elementos determinantes a la hora de componer esa atmósfera de bruto y crudo realismo. Este silencio, evocador de soledad, de fracaso, de violencia y muerte, incluso de ironía, es necesario en combinación con una música cuyas características la harían insostenible durante periodos prolongados. Las partituras para westerns de Morricone pocas veces alcanzan la hora de duración, incluso en los largos spaghetti de Sergio Leone ${ }^{80}$. Westerns que codificaron el género, para los cuales el director se inspiró en el cine japonés, de cuyo uso del silencio se valió para todas sus obras ${ }^{81}$, y que hubo de influir, por relación directa, en la música de Morricone. Este optó por utilizar solo este elemento en la interminable primera secuencia de Hasta que llegó su hora, en la que la armónica de Charles Bronson rompía de forma inquietante y contundente casi diez minutos de largo silencio. Lo mismo hace durante la primera gran secuencia de Una pistola para Ringo (Duccio Tessari, 1965), película en la que el silencio es predominante hasta límites insospechados en los dos primeros tercios. Y como Morricone, muchos de los compositores que trabajaron en el spaghetti y cuya principal referencia era el compositor romano.

Siendo Río Bravo una de las fuentes de Leone y de todo el spaghetti desde el punto de vista musical, y siendo los westerns de serie B una referencia importante, se podría establecer una relación entre el silencio reinante en unos y otros.

${ }^{80}$ Leinberger, 2004: 14.

81 "El cine japonés me fascina sobre todo por la utilización del silencio. Este confiere un tipo que me gusta mucho, muy particular, que no concede importancia al paso del tiempo [...] trabajando en el cine advertí que todos los directores estaban obsesionados con la velocidad [...] Me parecía artificial. En la vida real no es así. Se escucha, se reflexiona. Y después, se contesta. Esto lo encontré en el cine japonés, y me influyó mucho". Citado por Aguilar, 2009: 51. 


\section{Conclusiones}

Como hemos expuesto en este trabajo, el spaghetti western presenta características que le son propias. Entre otros apartados, cabe destacar el musical, muy reconocible y fácilmente vinculable a la copiosa producción de películas italianas de los años $60^{\prime}$ y $70^{\prime}$ ambientadas en el lejano Oeste. Ahora bien, así como Sergio Leone no perdía de vista las producciones del Oeste americano de la década anterior, tampoco lo hicieron los compositores que se dedicaron al género en Italia. Tal como Leone y Ennio Morricone reconocían, algunos elementos extraídos de películas americanas con música de Tiomkin eran material que sirvió como punto de partida para sus películas. En primer lugar, el "Degüello" que Tiomkin compuso para Río Bravo y utilizó al año siguiente en El Álamo, el cual sirvió de inspiración, tanto de forma puramente musical como simbólica, para los solos de trompeta de los duelos finales de la Trilogía del Dólar, que acabarían convirtiéndose en los temas más importantes de las mismas, y que generarían una enorme estela de seguidores en el spaghetti western. En segundo lugar, el uso dramático de las canciones y el elemento comercial de las bandas sonoras. Al igual que Tiomkin, quien fuera el pionero con Solo ante el peligro, Morricone compuso canciones para muchos de sus westerns, y sus bandas sonoras, tanto por estas como por la música incidental, se convirtieron en verdaderos éxitos de ventas. En tercer lugar, el uso de la voz humana, tan asociado a la música de Morricone, tiene muchos antecedentes en Tiomkin, quien ya adelantó numerosos recursos como los silbidos, gritos, susurros, vocalizaciones, onomatopeyas..., cuya función no va ser meramente estética, sino que van a tener una justificación dramática dentro de la historia. En cuarto lugar, la amplia paleta de color instrumental, en la que entran no solo instrumentos novedosos, sino nuevas formas de utilizar los instrumentos tradicionales y clásicos, dejando en muchas ocasiones a la orquesta en un segundo plano. En quinto lugar, la fusión de la diégesis con la música incidental, dando lugar a sonidos reales que parecen fundirse con la música instrumental y formar parte de ella, a la vez que participan de la diégesis. De esta forma, ambas dimensiones se terminan confundiendo, dando lugar a momentos de un alto potencial dramático y psicológico. Por último, el uso del silencio. Un recurso que Tiomkin llegó a emplear de forma magistral (todo lo que le dejaron) en una época en la que la amplitud de la banda sonora era una condición casi indispensable, y que Morricone, y en general todo el spaghetti western, tendrá muy en cuenta, encontrándonos partituras cortísimas en películas de gran metraje. 
Bibliografía

Adorno, Theodor/Eisler, H.: El cine y la música. Madrid: Fundamentos. (2005).

Aguilar, C.: Sergio Leone. Madrid: Cátedra. (1999).

Alunno, M.: "Reflexiones alrededor de la diégesis del sonido en el cine". En Relaciones música e imagen en los medios audiovisuales. Oviedo: Servicio de Publicaciones de la Universidad de Oviedo, 15-24. (2015).

Blanco, L.: "Música para el cine". En: Trama y fondo, 29, (2010), pp.45-59.

Bogdanovich, P.: John Ford. Berkeley: University of California Press. (1968).

Canby, V.: "Movie Review: Once Upon a Time in the West (1968)". The New York Times, May 29, 1969.

(1969).

En http://www.nytimes.com/movie/review?res=9E01E3DC1E3AEE34BC4151DFB3668382679 EDE $[29 / 11 / 2015]$.

Chion, M.: La música en el cine. Barcelona: Paidós Comunicación. (2010).

Colón Perales, C./Infante del Rosal, F./Lombardo Ortega, M.: Historia y Teoría de la Música en el Cine. Presencias afectivas. Sevilla: Ediciones Alfar. (1997).

Cooke, M.: A History of Film Music. Cambridge: Cambridge University Press. (2008).

Crowther, B.: "Movie Review: Fistful of Dollars (1964)". The New York Times, February 2, 1967. (1967). http://www.nytimes.com/movie/review?res=9B03E1DD1439E53BBC4A53DFB466838C679 EDE\&partner=Rotten\%2520Tomatoes [29/11/2015].

Crowther, B.:"Movie Review: For a Few Dollars More (1965)", The New York Times, July 4, 1967. (1967).En http://www.nytimes.com/movie/review?res=9F00E4D81F3CE43BBC4C53DFB166838C679 EDE $[7 / 12 / 2015]$

Cueto, R.: "El folklore imaginario". En: Nosferatu. Revista de Cine, 41, San Sebastián, (2002), pp.99117.

Cumbow, R. C.: The Films of Sergio Leone. Plymouth: Scarecrow Press. (1982).

Dibelius, U.: La música contemporánea a partir de 1945. Madrid: Akal. (2004).

Eleftheriotis, D.: Popular cinemas of Europe: studies of texts, contexts and frameworks. New York: Continuum. (2001).

Giddins, G.: Warning Shadows: Home alone with classic cinema. New York: W. W. Norton \&Company. (2010).

Gili, J.A.: Los grandes directores del cine. Barcelona: Manontroppo. (2006).

Graff, P. A.: Indian identity: case studies of three John Ford narrative westerns films. Dissertation, Pennsylvania State University, State College. (2013).

Hugues, H.: Spaghetti Western. Harpenden: Oldcastle Books. (2010).

Justo Estebaranz, Á./Pérez García, L.: "Del Japón feudal al planeta Akir: Estudio comparativo de la música en "Los siete samuráis" y sus remakes americanos". En Avanca/Cinema 2015. Avanca: Ediçoes Cine-Clube de Avanca, (2015), pp.159-166.

Kalinak, K.: How the West was sung: music in the Westerns of John Ford. Los Ángeles: University of California Press. (2007).

Kalinak, K.: Music in the Western: notes from the Frontier. New York: Routledge. (2012).

Kalinak, K.: "Tipically American: music from The searchers". En AA.VV The Searchers: essays and reflections on John Ford's classic Western. Michigan: Wayne State University Press. (2004).

Karlin, F.: Listening to movies. New York: Schirmer Books. (1994).

Konigsberg, I.: Diccionario técnico Akal de Cine. Madrid: AKAL. (2004). 
Lang, E./West, G.: Musical accompaniment of moving pictures. A practical manual for pianist and organist. And exposition of the principles underlying the musical interpretation of moving pictures. New York: The Boston Music Company. (1920).

Larsen, P.: Film music. London: Reaktion Books. (2007).

Leinberger, C.: Ennio Morrione's The Good, The Bad and The Ugly: a film score guide. Scarecrow Film Scores Guides, No. 3. Lanham: The Scarecrow Press. (2004).

Meuel, D.: The noir western: Darkness on the range, 1943-1962. Jefferson: McFarland. (2015).

Monelle, R.: The musical topic: hunt, military and pastoral. Bloomington: Indiana University Press. (2006).

Monelle, R.: The Sense of Music: Semiotic Essays. Princeton: Princeton University Press. (2000).

Morricone, E./Miceli, S.: Composing for the cinema: The theory and praxis of music in film. Lanham: Scarecrow Press. (2013).

Mouëllic, G.: La música en el cine. Barcelona: Paidós. (2011).

Neumeyer, D.: The Oxford Handbook of film music studies. Oxford: Oxford University Press. (2014).

Núñez Márquez, A.: Western a la europea, un plato que se sirve frío. Madrid: Entrelíneas Editores. (2006).

Padrol, J.: Pentagramas de pelicula: Entrevistas a grandes compositores de bandas sonoras. Madrid: Nuer. (1998)

Palmer, C.: The Composers in Hollywood. London: Marion Boyars Publishers. (1993).

Plastino, G.: "Provisionally popular. A conversation with Ennio Morricone”. En Made in Italy: studies in popular music. New York: Routledge, (2012), pp.223-233.

Román, A.: El lenguaje musivisual: semiótica y estética de la música cinematográfica. Madrid: Visión Libros. (2008).

Simmon, S.: The invention of the western film: A cultural bistory of the genre 's first. Cambridge: Cambridge University Press. (2003).

Smith, J.: The Sounds of Commerce: Marketing Popular Film Music. New York: Columbia University Press. (1998).

Tiomkin, D./Buranelli, P.: Please don't hate me. New York: Doubleday \& Company.(1959).

Walker, E.: Understanding sound tracks through film theory. Oxford: Oxford University Press. (2015).

Whitmer, M.: Jerome Moross's The big country: a film score guide. Maryland: Scarecrow Press. (2012).

Wierzbicki, J.: Film Music: A History. New York: Routledge. (2009)

Xalabarder, C.: Enciclopedia de las bandas sonoras. Barcelona: Grupo Zeta. (1997).

Xalabarder, C.: Música de cine. Una ilusión óptica. LibrosenRed. (2006).

Yoggy, G.A.: Back in the saddle: Essays on western films and television actors. Jefferson: McFarland. (1998). 